\title{
Application of a Hydraulic Actuator With Solenoid Valves for a Speed Control System
}

\author{
Abdullah H. M. AlBuzayd ${ }^{1}$, Nadhim M. Faleh ${ }^{2}$, Munaf Fathi Badr ${ }^{3}$ \\ ${ }^{1}$ Mechanical Engineering Department, College of Engineering, Mustansiriyah University \\ Baghdad, Iraq \\ Email: Easylove28 [AT] gmail.com \\ ${ }^{2}$ Mechanical Engineering Department, College of Engineering, Mustansiriyah University \\ Baghdad, Iraq \\ Email: Dr.nadhim [AT] uomustansiriyah.edu.iq \\ ${ }^{3}$ Mechanical Engineering Department, College of Engineering, Mustansiriyah University \\ Baghdad, Iraq \\ Email: Munaf [AT] uomustansiriyah.edu.iq
}

\begin{abstract}
This paper describes the design and the execution of a speed control system for a rotary hydraulic actuator by using solenoid valves. The design is to control the rotational velocity (or the speed) of a hydraulic motor without using neither a variable hydraulic pump nor a variable hydraulic motor. With analysis by the simulation using the package, $V 4.2 p / 1.67$ of FluidSIM 4 from FESTO. It is possible to predict the output of the rotational velocity (rpm) and next could take the right decision about the correct specifications of the system components to meet the requirements.
\end{abstract}

Keywords --- Control systems, Hydraulic actuator, Computer simulation

\section{INTRODUCTION}

Water was originally used as a power source for spin wheels and impulse levers, but the water did not satisfy the specifications because, relative to non-corrosive oil, it was not the right material for hydraulic pumps and hydraulic (Hydraulic Cylinders: A Brief History - Aggressive Hydraulics n.d.). One of the guidelines for extremely advanced development in modern applications is the control of hydraulic mechanisms and mechanical conveyance that could be practiced in machines and machinery (Tran, Le, and Ngo 2017). Due to the complexity, and dynamic and randombehavior of many control, manufacturing systems, or other engineering systems, it has become an urgent necessity before carrying out design work. To conduct a thorough study similar to the system to be manufactured and to do experiments that are done through computer programs for simulation and as a result reach the requirements (Baldwin et al. 2000). Many areas could be as a place for applications of simulation, such as natural resources, manufacturing processes, health care, military industrials, computer systemanaly sis, means of transportation, reverse en gineering, and more. It gives a simple approach to take care of complex genuine issues. As of now, the market is immers ing with a wide scope of recreation programming bundles. Such bundles reflect fluctuating properties, for example, quality, highlights, dis playing approaches, techniques sent, and cost of productivity, etc. Accordingly, choosing a reasonable recreation bundle is turning into a difficult issue. Clients need skill or the ability to choose which bundle will be appropriate for their applications (Alomair, Ahmad, and Alghamdi2015).

Fundamentally, there are two classes of hydrau lic transmis sion circuits broadly used in manufacture: controlling by valve(s) and controlling by pump(s). The first kind utilizes a hydraulic valve(s) as a controller when a hy draulic pump works at a steady speed which explains it gives a steady flow rate. Because of the high-performance quality, this type of circuits is used widely in industries. The second kind of the circuits, Simply put, a hydraulic pump is directly connected to a hydraulic motor, so that the hydraulic pump has two necessary tasks: the first is to generate hydraulic pressure and flow, and the second acts as controlling the hydraulic motor. A clas sic hydraulic circuit controlled by a valve is indicated in fig. $1[5,6]$. 


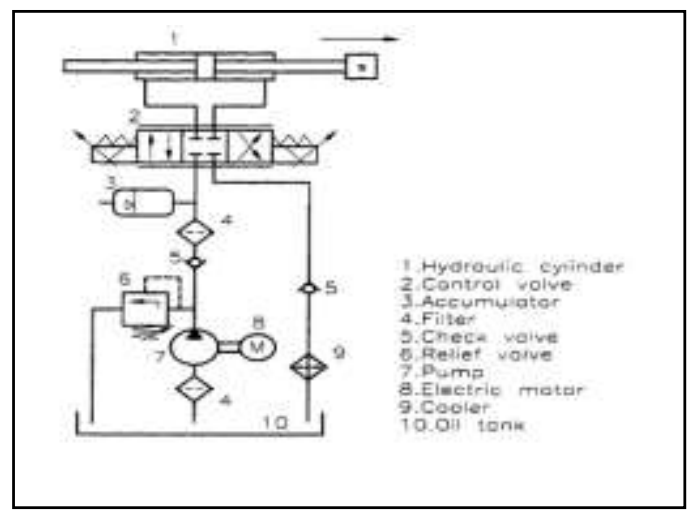

Fig. 1: Schematic diagram of a typical valve-controlled circuit

By using a meter-out speed controlcircuit, the flow controlvalve will get an effective area bigger than that of a meter-in speed control circuit, and the applied pressure needs to be much higher than the pressure required to rotate or move the load as it has addition to conquer the returned pressure in the actuator chamber. But in a meter-in speed control circuit, the pressure res ponse will be more os cillatory comparing to the meter-out speed control circuit when driving the actuator at high speeds $[7,8]$.

\section{DESCRIPTION OF EXPERIMENTAL EQUIPMENTS}

The tes ted practical systemis indicated in fig. 2 its represents a closed systemfor hydraulic rotation and an open systemfor control. A hydraulic res ervoir No. 1 plays a very important role, as it carries most parts of the control system, as well as contains the hydraulic pump and the filter piece in addition to the hydraulic oil its elf. An electric motor No. 2 has a $0.75 \mathrm{~kW}$ is coupled with a fixed hydraulic gearpump (c18x class) is not shown in fig. 2 . A 4/2-way valve No. 3 is a principle directional control valve (DCV) to control the hydraulic input to other valves and als o to work on the possibility of rotating the hydraulic in the direction of the tank if none of the other valves is activated. A pressure relief valve No. 4 is used as a regulator valve to protect the system from exces sive pressure. 4/3-way No. 5 three directional control valves (DCVs), are double solenoids, three positions, springs centered. Throttle and check modular valves No. 6 are two flow control valves to control the flow rate in a meter-out way. A pressure gauge No. 7 to indicate the system pressure. A thermometer No. 8 to show the temperature of the hydraulic inside the reserv oir No. 1. A flow meter No. 9 to read the liters of the hydraulic oil in a minute. A hydraulic motor No. 10 from DANFOSS has a $97.3 \mathrm{ccm}$, to convert the hydraulic power into mechanical power. An example of a mixer application No. 11.

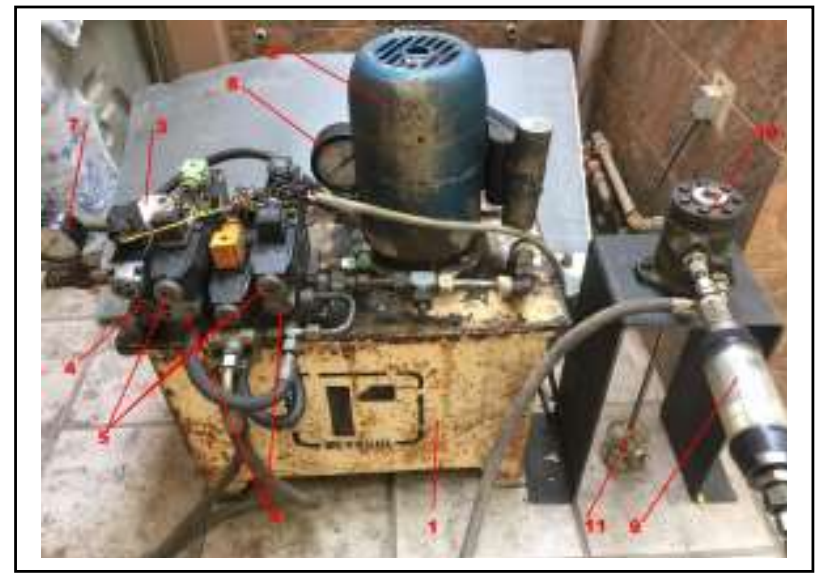

Fig. 2: Practical speedcontrol system

\section{ANALYSIS OF SIMULATION}

The tes ted experimental systemis represented by the schematic diagramas shown in fig. 3 . The pres sure source of the hydraulic is signified by the hydraulic fixed dis placement gear pump No. 1, which also is used to rotate thehydraulic motorNo.9. The valve No. 2 is a press ure relief valve to protect the system. At normal conditions, the pump No. 1 pushes all the hydraulic towards the hydraulic motor No. 10 without the need to operate the relief valve No. 2 . No. 3 valve is a 4/2-way directional control valve, it is the principle valve. The three valves No. 4, No. 5, and No. 6 are 4/3-way directional control valves, closed center with double solenoids. No. 7 and No. 8 are flow control valves from the throttle and check 
valve type. A flow meter No. 9 to show the flow rate values. Finally, a hydraulic motor No. 10, is two directions rotary motor.

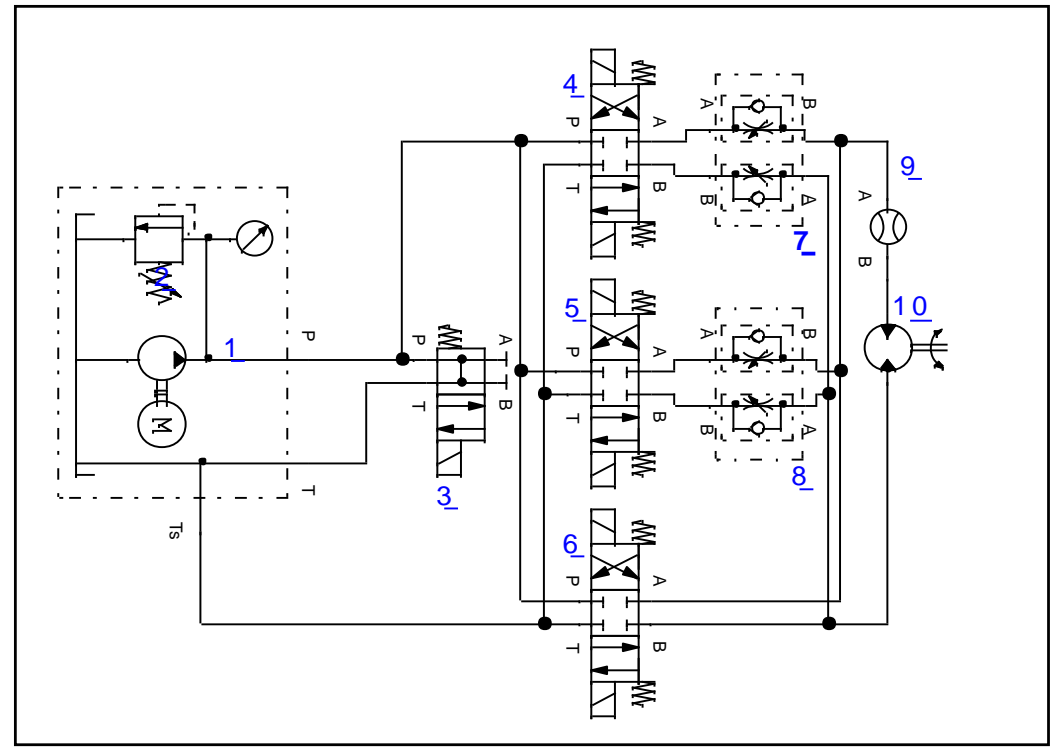

Fig. 3: A schematic diagramfor simulation of the speed control system

Fig. 4 indicates the working specifications curve of a fixed displacement pump, a fixed displacement motor, and other changeable parameters.

The displacement of the hydraulic pump is unchanged but can change its speed and the pressure of the system. The dis placement of the hydraulic motor is a fixed one, the output speed is proportional to each of the speed of the pump and system pressure, but it is proportional to the negative values of the external torque when actuating the right side of the $4 / 3-$ way DCV.

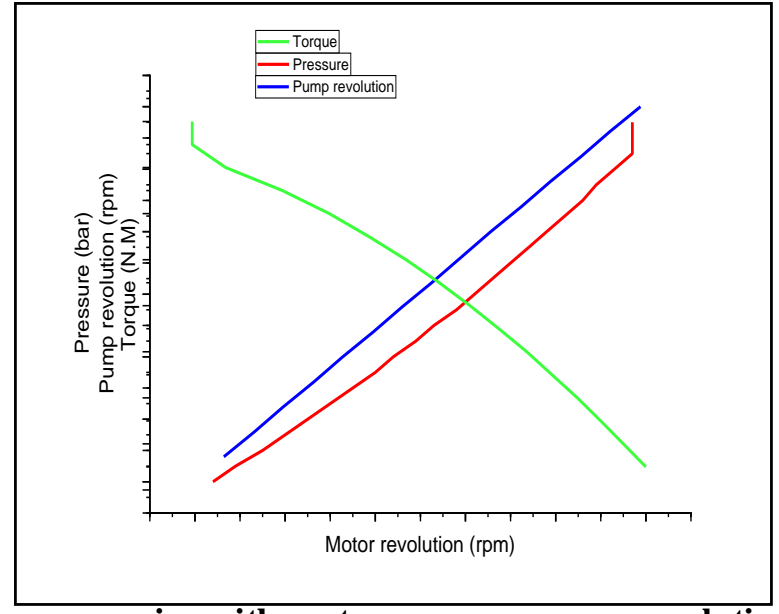

Fig. 4: Motor behaviors comparing with system pressure, pump revolution, and external torque.

\section{A. System diagram and simulation}

As was indicated previously in fig. 3, the full simulation of the speed control system which consists of the fixed dis placements motor and the fixed dis placement pump. The fixed dis placement hydraulic pump takes its rotary speed from the electric motor and pushes the hydraulic oil to convert the mechanical energy in to hydraulic energy towards the hydraulic motor. This process takes place through a series of procedures through several mechanical components to control pressures and flow rates, and as a result, the desired outcome is reached. The systemparameters are indicated in table 1. 
Table 1: The specifications of the speed control system components

\begin{tabular}{|c|c|c|c|}
\hline \multirow{2}{*}{ Item } & \multicolumn{3}{|c|}{ Sys tem parameters } \\
\hline & Parameter description & Value or Position & Unit \\
\hline 1 & $\begin{array}{l}\text { Displacement of the fixed } \\
\text { displacement pump }\end{array}$ & 8 & $\mathrm{Cm}^{3} / \mathrm{rev}$ \\
\hline 2 & Pres sure relief valve & 230 & Bar \\
\hline 3 & 4/2-way DCV & $\mathrm{I} / \mathrm{O}$ & Null \\
\hline $4,5,6$ & $\begin{array}{l}\text { 4/3-way double solenoid, } \\
\text { center closed valve. }\end{array}$ & $\mathrm{A}, \mathrm{O}, \mathrm{B}$. & Null \\
\hline 7,8 & $\begin{array}{l}\text { Throttle and check valve } \\
\text { for } A \& B \text { lines. }\end{array}$ & $0-100 \%$ & Null \\
\hline 9 & $\begin{array}{l}\text { Displacement of the fixed } \\
\text { motor }\end{array}$ & 97.3 & $\mathrm{Cm}^{3} / \mathrm{rev}$ \\
\hline
\end{tabular}

\section{B. The analysis of the system simulation}

According to fig. 3 of the full sys tem, the hydraulic pump No. 1 pushes the hydraulic towards the valve No. 3, in the case of no actuating of any one of the three valves No. 4, 5, and 6, the hydraulic will go back to the tank which means an important circulation of the hydraulic. If anyone of the three 4/3-way DCVs are activated, the hydraulic will reach the hydraulic motor No. 9 and rotate it in a speed depends on the opening level of the throttle valves No. 7 and No. 8 after actuating No. 4 or No. 5 valve respectively, or in a maximum speed after actuating No. 6. Because there is no throttle valve after valve No. 6, almost whole the hydraulic will arrive at the motor No. 9. Fig. 5 shows how the speed of the hydraulic motor acts during the time. The following values were adopted while drawing the fig. 5 (the speed of the hydraulic pump is $2400 \mathrm{rpm}$, maximum pres sure of the systemis 50 bar, internal leakage in the hydraulic pump is zero, the hydraulic motor has noexternal torque, the opening levels of the throttle-check valves No. 7 and No. 8 are $15 \%$ and $20 \%$ respectively. The speeds of the motordo not affect the time.

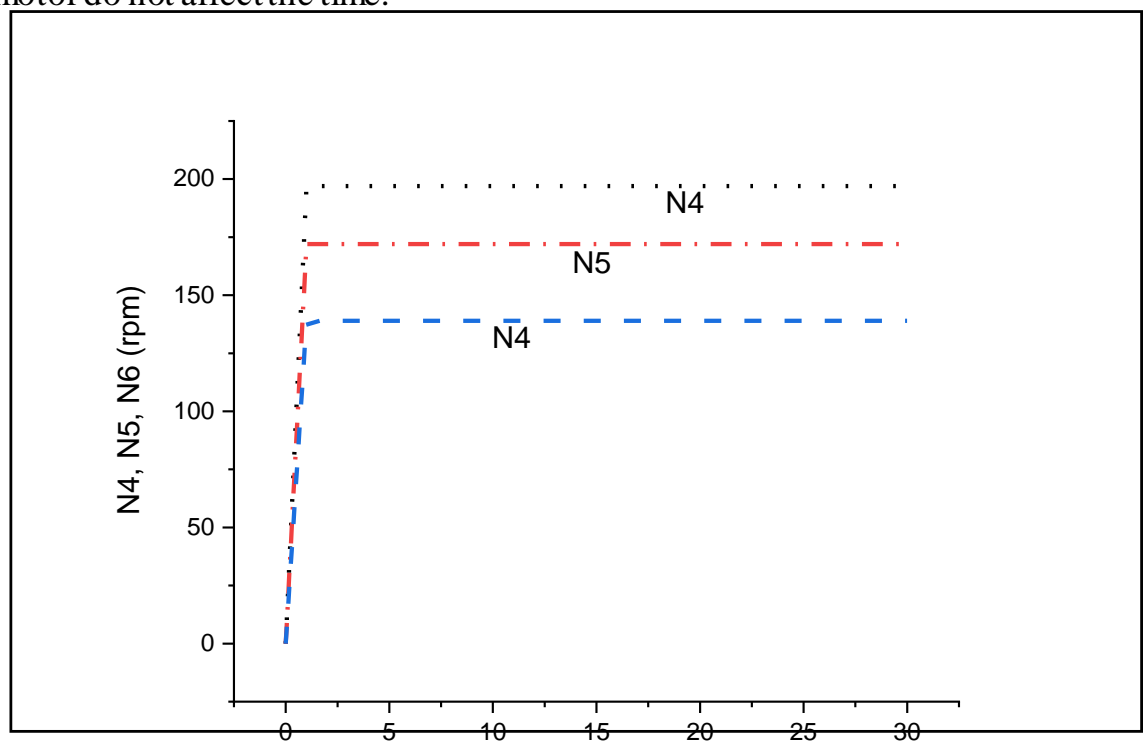

Fig. 5: Motor speedshdursigg) a range of time ${ }^{1}$

1) The effects of changing the systempressure on the hydraulic motor speed where there wasn't an external torque.

The rotary speed of the hydraulic pump is fixed at $2400 \mathrm{rpm}$. A variable range of pressures was taken from 1) bar to 105 bar, also the throttle-check valves No. $7 \&$ No.8 are limited to $15 \%$ \& $20 \%$ respectively. When valve No. 4 is activated, the hydraulic motor No. 9 takes different values of rotation depending on the systempressure, starting from 31 rpm and up to $197 \mathrm{rpm}$ and pressures starting from 1 bar to 105 bar. Whereas, if valve No. 5 is activated, the hydraulic motor will take rotational values start from $38 \mathrm{rpm}$ and up to $197 \mathrm{rpm}$ and pres sures starting from $1 \mathrm{bar}$ and up to $65 \mathrm{bar}$. Finally, we noticed when the valve No. 6 is activated, the hydraulic motor rotates at a rotational speed starting from 68 rpm and up to 197 rpm under pressures starting from 1 bar and up to 20 bar only. Fig. 6 shows graphically what has been explained.

\footnotetext{
${ }^{1} \mathrm{~N} 4, \mathrm{~N} 5$, and N6: Speeds of the hydraulic motor when actuating the valves 4, 5, and 6 res pectively.
} 


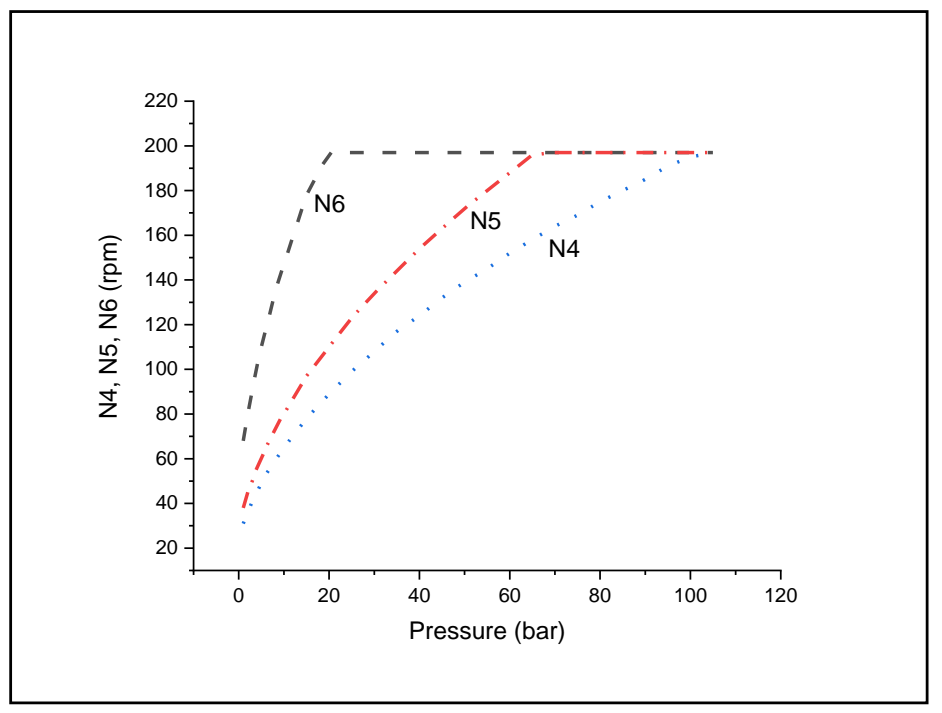

Fig. 6: Speeds of hydraulic motor VS Pressure

2) the effects of the changing of the pump speed on the speed of the motor without external torque.

Fig. 7 shows a diagram to explain the relationship of the hydraulic pump speed with the hydraulic motor speed without external torque. We noticed that the hydraulic motor speed linearly proportional to the hydraulic pump speed and does not change at changing the valve No. 4, No. 5, or No. 6 at applying different speeds on the hydraulic pump between 125 and $1625 \mathrm{rpm}$. From $1750 \mathrm{rpm}$ pump speed and up, the speed of the hydraulic motor will stay constant at $138 \mathrm{rpm}$ if we actuate the No. 4 valve. but still have linearly proportional between the two speeds of the pump and the motor when actuating any one of the two valves No. 5 or No.6 until $2125 \mathrm{rpm}$ of the pump speed we will get a maximum speed of the hydraulic motor $172 \mathrm{rpm}$ for the valve No. 5. This speed will contin ue and does not matter about the hydraulic pump speed increasing. For valve No. 6 the motor speed will stay linearly proportional to the speed of the pump.

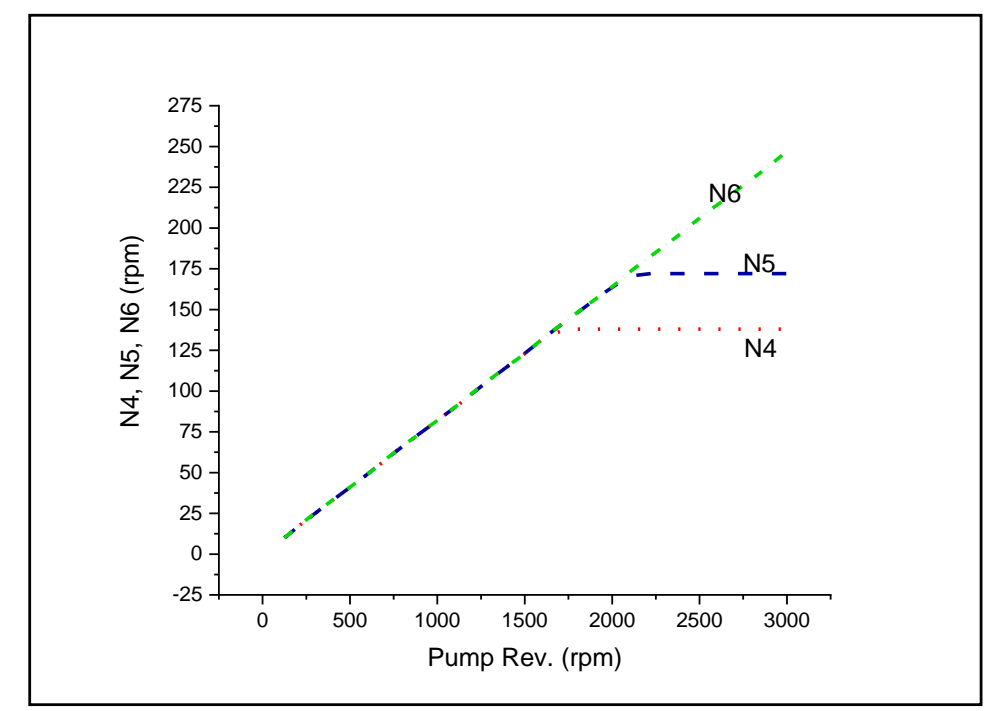

Fig. 7: Speed of the motor VS pump revolution

3) The analy sis of the hydraulic motor speed after applying a range of external torques.

In this simulation, the following parameters were used in the fig.. 8 maximum pressure is $50 \mathrm{bar}$, speed of the hydraulic pump is $2400 \mathrm{rpm}$, the range of external torques is in between 0 and -200 N.M, the opening levels of the valve No. 7 and No. 8 are $15 \%$ and $20 \%$ respectively. The hydraulic motor speed was calculated for each torsion torque and each activation state for one of the three valves 4,5 , and 6. Fig. 8 shows that the hydraulic motor rotates at variable speeds, where the speed of the hydraulic motor is proportional to the negative values of the external torques, and the speed varies according to the valve that is energized. When activating the No. 4 or No. 5 valve, it was observed that the speed of the hydraulic motor remains constant at specific external torsional torques are applied and after that, the motor speed changes, 
while when the No.6 valve is activated, the hydraulic motor speed increases directly with the increase of the negative external torsion torque.

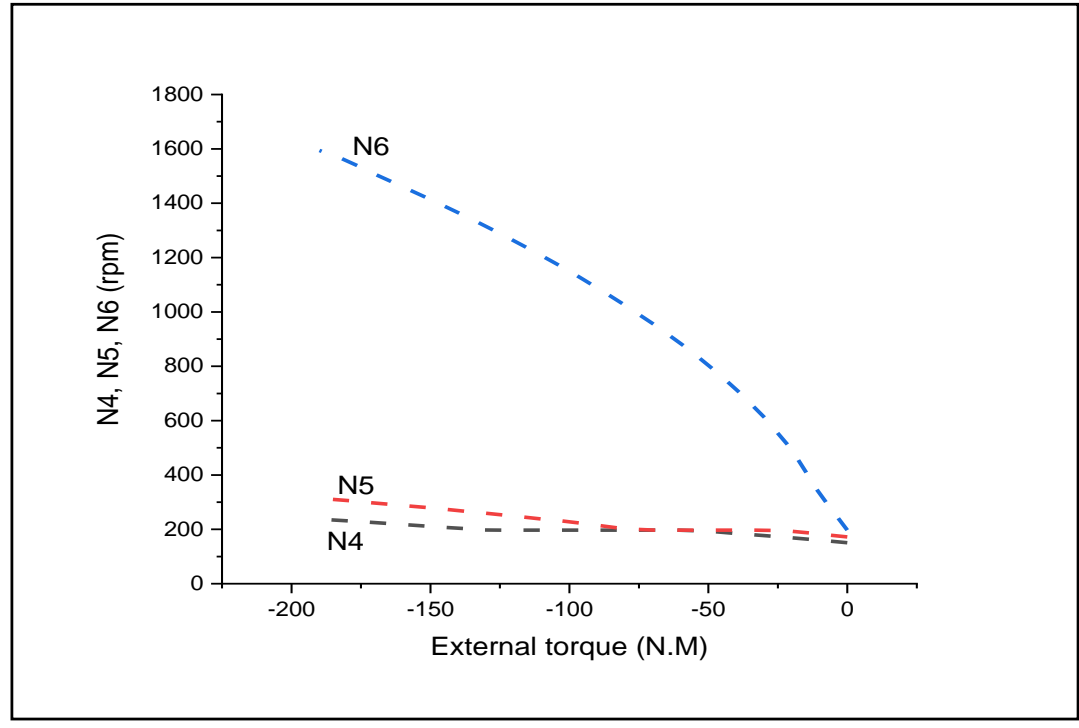

Fig. 8:Speed of motor VS external torque

4) The analy sis of the speed of the hydrau lic motor after applying a range of pressures with an external torque.

At this simulation, the following data were us ed in fig. 9 a range frompress ure from 1 to $70 \mathrm{bar}$, the speed of the hydraulic motor is $2400 \mathrm{rpm}$, the applied external torque is $-50 \mathrm{~N} . \mathrm{m}$, the opening levels of the valve No.7 and No. 8 are $15 \%$ and $20 \%$ res pectively. It was observed that the speed of the hydraulic motor after actuating any valve of No. 4 or No. 5 valves, the speed linearly proportions with the pressure for some values and then starts to stable horizontally. But for the No. 6, if it actuates, we notice that the hydraulic motor speed does not affect the changing of the pressure along the time and there is a huge difference comparing with the results of the two valves No. 4 and No. 5 .

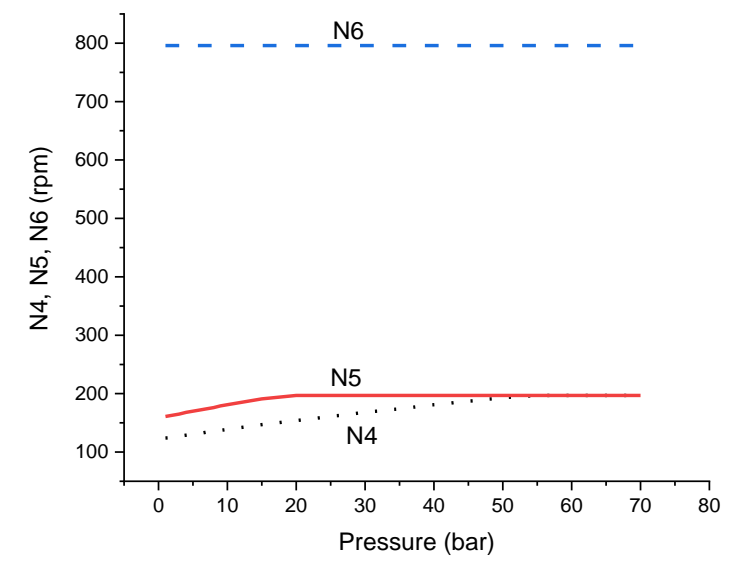

Fig. 9: Speed of motor VS Pressures with an external torque

5) The analysis of the speed of the hydraulic motor after applying a range of pump speeds with existed of an external torque.

This time, fig. 10 shows the simulation utilized the following data the pressure systemis 50 bar, the speed of the pump is from 125 up to $3000 \mathrm{rpm}$, the external torque is -50 N.m, the opening levels of the valve No. 7 and No. 8 are $15 \%$ and $20 \%$ respectively. The speed of the hydraulic motor differents from actuated valve to another one according to the opening level of the throttle-check valve, if the valve No.4, is actuated the speed of the hydraulic motor will be fixed at $120 \mathrm{rpm}$ under the range 125 - $1250 \mathrm{rpm}$ of the hydraulic pump speed, and that we noticed, the speed of the motor started in raising gradually from 123 up to $193 \mathrm{rpm}$ under the speeds of the pump 1500 up to $2375 \mathrm{rpm}$, finally, the motor was stabled at $193 \mathrm{rpm}$ regardless to the increasing of the speed of the pump from 2375 and more. Whilst, if the valve No. 5 is 
actuated, and applying a range of pump speeds between 125 and $1875 \mathrm{rpm}$ the speed of the motor was steady at $159 \mathrm{rpm}$. But the speed of the motor is increased linearly starting fromapplying $2000 \mathrm{rpm}$ to the pump. As for the valve No. 6, the motor s peed remains unchanged, regardless of the rotational s peed value of the pump.

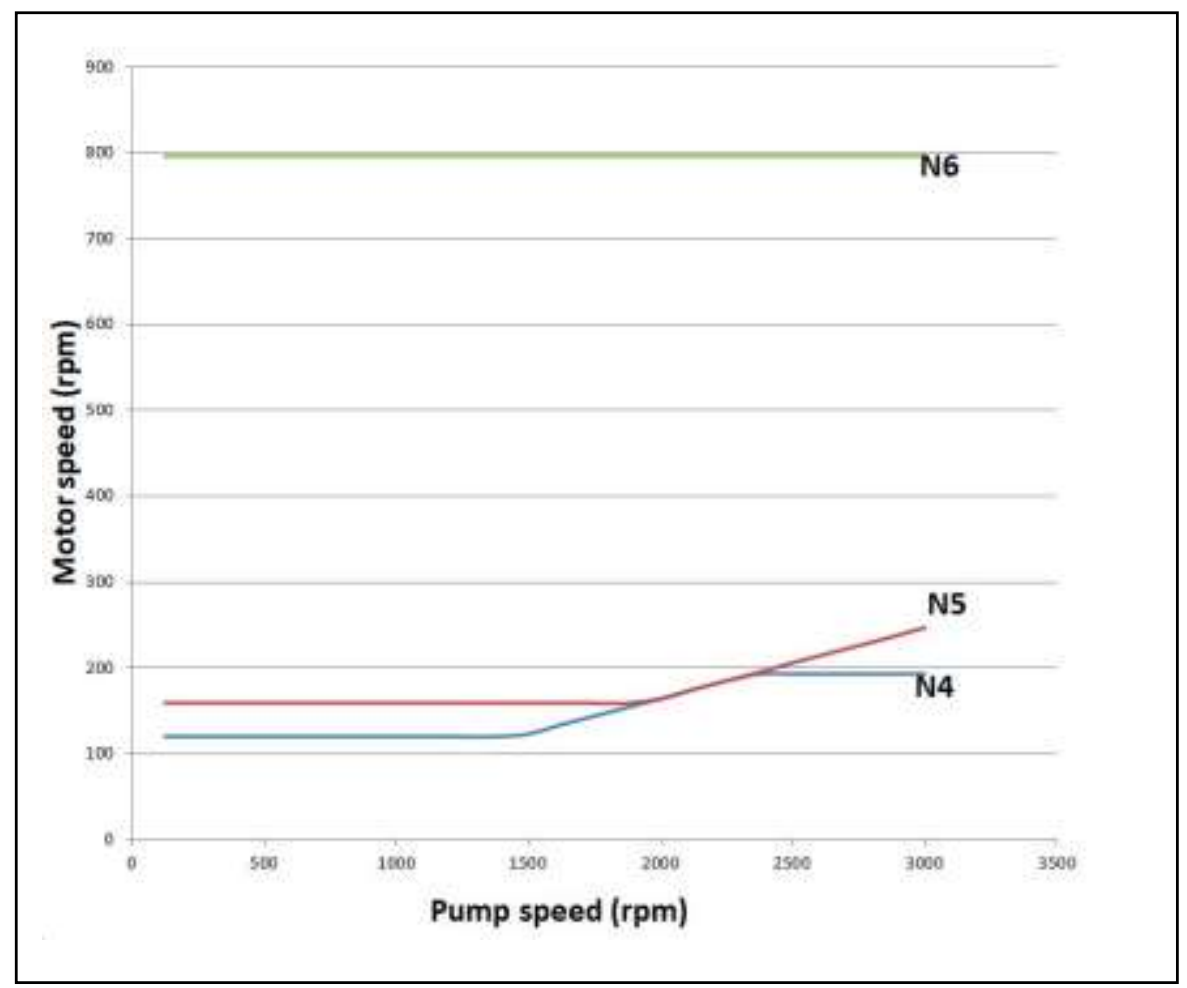

Fig. 10: Motor speed VS a range of pump speed

\section{DISCUSSION}

According to fig. 3, the following information are lis ted to clarify how data are collected to use in the simulation:

1) All parameters related to the hydraulic pump No. 1, were according to the Fiat catalog and Hydrocap website(Hydraulic Gear Pump - C10X - Hydrocap n.d.).

2) The data of the hydraulic motor "Danfoss" No.9, were collected from the Danfoss website (Copy and Chk2013).

3) 4/3-way solenoid valves No. 4, No.5, and No. 6, from Parker. All specifications were collected from the main home page (Directional Control Valve - Series D1VW / D1VW*EE | United Arab Emirates \& Middle East n.d.).

4) 4/2-way solenoid valve No. 3, from REXROTH, all its specifications were from the main home page (MediaDirectory | Bosch Rexroth AGn.d.), it was used to protect the three valves 4/3-way (mentioned above), and also to give the possibility to circulate the hydraulic if none of the three valves was activated because they are center-closed type.

5) The specifications of the pressure relief valve No. 2, from ATOS HM - 012/120 are dependent on the home page (Code and Characteris tics n.d.).

6) Both of the throttle-check valves No. 7, and No. 8, are from Yuken MSW-01-X-30 to control theflow rates that come from valves No. 4, and No. 5 res pectively, these types of throttle give a meter-out circuit design (Plate and Mil n.d.).

7) The negative values of externaltorques represent a clockwise direction.

8) The rotational speeds of the hydraulic motor are recorded when only the right-portion b from the 4/3-way valves are activated.

9) Resistance losses were neglected for: pipes and hoses lengths, gauges, connections.

10) Temperatures were neglected and changes in hydraulic density were not taken into account

\section{CONCLUSIONS}

The main goal of the design was executed successfully, e.g. three rotational speeds of the rotary hydraulic actuator are obtained through the use of directional control valves and throttle valves. All results were approximate because the 
simulation as sumed that all devices and equipment were operating at optimumefficiency without losses. From what was presented in the above, and by noting the pros and comparing them with the cons of simulation programs and their uses in engineering applications, for example, designs of hydraulic systems, it proved that the advantages are very good, large, and very useful. The cons can be avoided although they are few compared to the great benefit. These simulation programs are considered a cheap and effective tool because of the services they provide that can reduce the effort, time, and cost.

\section{REFERENCES}

- Alomair, Yasmeen, Iftikhar Ahmad, and Abdullah Alghamdi. 2015. "A Review of Evaluation Methods and Techniques for Simulation Packages.” Procedia Computer Science 62(Scse): 249-56. http://dx.doi.org/10.1016/j.procs.2015.08.447.

- Badr, M. F. 2018. "Modelling and Simulation of a Controlled Solenoid." IOP Conference Series: Materials Science and Engineering 433(1).

- Badr, MunafF. 2012. "Employing Analogue and Digital Solenoid Hydraulic Valves in Position Control System." 16(3): 269-86.

- $\quad$ Baldwin, L.P., T. Eldabi, V. Hlupic, and Z. Irani. 2000. "Enhancing Simulation Software for Use in Manufacturing." Logistics Information Management 13(5):263-70.

- Code, Model, and Hydraulic Characteristics. "Modular Relief Valves Type HMP , HM, KM.” : 10-13.

- Copy, Official, and S B M Offshore N V Chk. 2013. “Orbital Motors Type OMP, OMR and OMH Technical Information.": $1-96$.

- "Directional Control Valve - Series D1VW / D1VW*EE | United Arab Emirates \& Middle East." https://ph.parker.com/ae/en/directional-control-valve-series-d1vw-d1vw-ee (September 17, 2020).

- "Hydraulic Cylinders: A Brief His tory - Aggressive Hydraulics." https://www.ag gressivehydraulics .com/hydraulic-cylinders-a-brief-history/ (September 4, 2020).

- "Hydraulic GearPump - C10X - Hydrocap." https://hydrocap.net/en/c/acx-132/hydraulic-gear-pump-c10x-620 (September 17, 2020).

- Kim, Do-Tae. 2013. "A Study on the Meter-Out and Meter-In Speed Control Characteris tics in Pneumatic Cus hion Cylinders.” Journalof The Korean Society of Manufacturing Technology Engineers 22(1): 1-7.

- "Media-Directory|Bosch Rexroth AG." https://www.boschrexroth.com/en/xc/myrexroth/mediadirectory?language=enGB\&publication=NET\&search_query=23177\&search_action=submit (September 17, 2020).

- Pastrakuljic, Vladimir. 1995. "Design and Modeling of a New Eleciro Hydraulic Actuator.” : 137.

- Plate, Sandwich, and Type Z F S Mil. "Throttle and Throttle Check Valve.” : 219052.

- Tran, N. H., C. Le, and A. D. Ngo. 2017. "Experimental Investigation of Speed Control of Hyd raulic Motor Using Proportional Valve.” Proceedings - 2017 International Conference on System Science and Engineering, ICSSE 2017:330-35. 